\title{
Article \\ Burden of Endometriosis: Infertility, Comorbidities, and Healthcare Resource Utilization
}

\author{
Vered H. Eisenberg ${ }^{1, *(D)}$, Dean H. Decter ${ }^{1}$, Gabriel Chodick ${ }^{2}$, Varda Shalev ${ }^{2}$ and Clara Weil $^{2}$ \\ 1 Sheba Medeical Center, Sackler Faculty of Medicine, Tel Aviv University, Tel Aviv 6997801, Israel \\ 2 Maccabi Institute for Research and Innovation, Maccabi Healthcare Services, Sackler Faculty of Medicine, \\ Tel Aviv University, Tel Aviv 6997801, Israel \\ * Correspondence: vered.eisenberg@sheba.health.gov.il; Tel.: +972-52-666-8452
}

Citation: Eisenberg, V.H.; Decter, D.H.; Chodick, G.; Shalev, V.; Weil, C. Burden of Endometriosis: Infertility, Comorbidities, and Healthcare Resource Utilization. J. Clin. Med. 2022, 11, 1133. https://doi.org/ $10.3390 /$ jcm11041133

Academic Editors: Jacek Malejczyk, Camran R. Nezhat and Eyal Sheiner

Received: 16 January 2022

Accepted: 16 February 2022

Published: 21 February 2022

Publisher's Note: MDPI stays neutral with regard to jurisdictional claims in published maps and institutional affiliations.

Copyright: (c) 2022 by the authors. Licensee MDPI, Basel, Switzerland. This article is an open access article distributed under the terms and conditions of the Creative Commons Attribution (CC BY) license (https:// creativecommons.org/licenses/by/ $4.0 /)$.

\begin{abstract}
The goal of our study was to evaluate the burden of endometriosis in the community by comparing healthcare resource utilization, total direct medical costs, infertility, and comorbidity rates of women with and without a diagnosis of endometriosis. A retrospective case-control study was performed using the databases of a 2.1 million-member nationwide healthcare plan. The study population included women aged 15-55 years enrolled in the healthcare plan. Women with a diagnosis (ICD-9) of endometriosis were compared to controls without diagnosed endometriosis. Women were individually matched (1:4) on age and residence area. Patient characteristics were described, including infertility, comorbidities, and annual healthcare resource utilization. Total direct medical costs were analyzed in a generalized linear model adjusting for age. Women with endometriosis ( $n=6146$, mean age \pm SD: $40.4 \pm 8.0$ y) were significantly more likely than controls $(n=24,572)$ to have a lower BMI and a higher socioeconomic status. After adjusting for BMI and socioeconomic status, endometriosis was significantly associated with infertility $(\mathrm{OR}=3.3 ; 95 \% \mathrm{CI}$ 3.1-3.5), chronic comorbidities, higher utilization of healthcare services (hospitalization: $\mathrm{OR}=2.3$; 95\% CI 2.1-2.5), pain medications, and antidepressants. Women aged 15-19 y with endometriosis had substantially higher utilization of primary care visits ( $57.7 \%$ vs. $14.4 \%)$ and oral contraceptive use $(76.9 \%$ vs. $9.6 \%)$. Direct medical costs associated with endometriosis were higher than those for controls $(\mathrm{OR}=1.75$; 95\% CI 1.69-1.85). Endometriosis is associated with a high burden of comorbidities, increased healthcare resource utilization, and excess costs, particularly for younger patients whose healthcare needs may differ widely from the older population.
\end{abstract}

Keywords: endometriosis; infertility; co-morbidities; burden; healthcare resource utilization; real world data; epidemiology; adolescents; young adults

\section{Introduction}

Endometriosis is a benign gynecological condition defined as the presence of endometriallike glands and stroma outside of the uterus [1]. The prevalence of endometriosis is approximately $10 \%$ [2,3]; however, estimates differ widely due to varying study populations and designs [4]. In line with population-based estimates from European databases (range $0.8-1.8 \%$ ) [5,6], the prevalence of diagnosed endometriosis has been reported as 10.8 per 1000 (95\% CI 10.5-11.0) [7], which is lower than estimates based on high-risk populations.

Symptoms of endometriosis include chronic pelvic pain, dysmenorrhea, dyspareunia, dysuria, dyschezia, and subfertility [1,3]. Symptoms may appear years before diagnosis [8], resulting in an average 10-year delay $[2,6,9]$. The gold standard for diagnosis includes laparoscopy with or without biopsy; however, there is support for treating symptoms prior to definitive surgical diagnosis [10]. There are arguments for shifting diagnosis away from surgical and more towards clinical aims to focus more on the patient and less on the lesion to reduce the cost and diagnostic delay [10-12]. Pain-relieving and hormonal medications are frequently used in treatment [13]. Endometriosis patients may pay an average of seven 
visits [2] to a general practitioner before being referred to a specialist and may undergo symptom treatment without a confirmed diagnosis [14], contributing to the burden on healthcare resources.

There are relatively few studies on endometriosis in adolescent women [15]. Little is known about this disease in adolescent women, and an earlier diagnosis may improve outcomes to reduce chronic pain and improve quality of life. The present study aimed to assess the burden of endometriosis by comparing healthcare resource utilization (HCRU), total direct medical costs, infertility, and comorbidity rates of women with and without an endometriosis diagnosis.

\section{Materials and Methods}

We conducted a retrospective population-based case-control study using the computerized databases of the local healthcare service. The database includes approximately 2 million active members nationwide and represents $25 \%$ of the national population with similar sociodemographic characteristics [16]. Data sources are described in detail in another publication [7].

Women with endometriosis were identified according to diagnosis codes (International Classification of Disease, 9th Edition, clinical modification (ICD-9): 617.xx) from a primary care physician (PCP) (general practitioner, pediatrician, gynecologist), or another specialist from 1998 to 2015 . The study population consisted of women aged 15-55 years on 31 December 2015, with diagnosed endometriosis and at least 12 months of continuous enrollment in the health plan. While the results of imaging and surgical evaluation were not used for validating the diagnosis, more than $90 \%$ had a previous record of a pelvic/gynecological US examination. This population and the validity of case ascertainment methods are described in detail in another study [7]. For comparison of patient characteristics and healthcare resource utilization, controls were selected from the database's general population with no record of endometriosis and individually matched (1:4) on age (5-year groups) and residential area.

Data were obtained on patients' age, region of residence (Northern/Center/Southern regions), and socioeconomic status (SES). SES was based on a commercial geographic index (range: 1-10) developed by Points Ltd., which is correlated with the residence-based SES from the local Central Bureau of Statistics [17]. SES was classified into low (1-3), medium (4-6), and high (7-10). Body mass index (BMI) categories were based on WHO recommended cut-off points [18].

Broad coverage of infertility assistance is provided in the National Basket of Health Services. Data were extracted from the healthcare database infertility registry which integrates data on subfertility or infertility diagnoses, fertility treatments in hospital or community clinics (including in vitro fertilization, ovarian stimulation procedures, and oocyte donation), and dispensed fertility medications [19].

Data on chronic comorbidities were obtained from previously validated registries for cardiovascular disease (CVD) [20], diabetes [21], hypertension [22], and chronic kidney disease (CKD) [23], and from the National Cancer Registry [24]. The Deyo-Charlson Comorbidity Index (CCI) [25], based on ICD-9 codes, was modified to include additional data from the healthcare service chronic disease registries. Smoking status was obtained from physician reports. Inflammatory bowel disease (IBD) was described using ICD-9 codes. We described diagnoses of conditions with potentially overlapping symptoms, which may be associated with or misdiagnosed as endometriosis, including appendicitis, irritable bowel syndrome (IBS), and unspecified bladder disorders.

To evaluate HCRU, the frequency of hospitalization and visits to PCPs and gynecologists was described. Use of pain medications was defined as at least 2 dispensed prescriptions in one year, according to the following categories: nonsteroidal anti-inflammatory drugs (NSAIDs); paracetamol (PAR), acetylsalicylic acid (ASA), or dipyrone; codeine combined with either PAR or ASA; tramadol. Use of antidepressants was defined as at least 2 dispensed prescriptions of selective serotonin reuptake inhibitors, or tricyclic or other 
antidepressants. Data were also obtained on dispensed oral contraceptives, gonadotropin medication, and insertion of hormone-releasing intrauterine devices (IUDs). Laboratory testing rates were described for complete blood tests (CBC), serum iron, luteinizing hormone (LH), follicle-stimulating hormone (FSH), and cancer antigens (CA-125 and CA-15.3). Utilization of magnetic resonance imaging (MRI) and transvaginal ultrasound (TVUS), including utilization of a dedicated endometriosis TVUS (E-TVUS), was described. The impact on work productivity, school attendance, and performance of daily activities [2] was not within the scope of the current study.

Total annual direct medical costs were obtained from the local healthcare service database, as described in previous cost-of-illness studies [26]. Briefly, most services in the local healthcare service are delivered via third-party providers, and annual costs are routinely calculated in the accounting system as the sum of all services provided, including per diem hospitalization rates, physician visit reimbursements, emergency room visits, laboratory tests, procedures, and hospital outpatient charges. Out-of-pocket expenses and services provided directly by the state, such as hospital birthing costs and certain mental healthcare services, were not captured. Costs were translated into cost units to avoid disclosure of internal corporate information.

Patient characteristics: Descriptive statistics were generated for analysis variables, including frequency distributions for categorical variables $(n ; \%)$, and mean values with standard deviations (SD) or medians with interquartile ranges (IQRs) for continuous variables. Differences between groups were tested using the $\chi^{2}$ test, t-test, or median test. Odds ratios (ORs) and 95\% confidence intervals (CIs) were computed in a conditional logistic regression, adjusting for SES and BMI. A generalized linear model (gamma distribution with log link) with log-transformed cost, adjusting for age (cubic), was used to estimate predicted costs in both groups and to calculate the adjusted OR (95\% CI) associated with endometriosis. Analyses were performed with IBM-SPSS version 24 (IBM Corp. Released 2013. IBM SPSS Statistics for Windows, Version 22.0. Armonk, NY, USA: IBM Corp.).

The study was approved by the institutional review board (reference number 2016027). Written informed consent was not required as this was a retrospective database analysis.

\section{Results}

A total of 6146 women aged 15-55 were included in the endometriosis prevalence population (mean age \pm SD: $40.4 \pm 8.0$ ), and 24,572 women were included in the matched control group. Compared to controls, women with endometriosis were significantly more likely to have a higher SES and a lower BMI and reside in the Central region, and less likely to live in areas with predominantly religious orthodox Haredi or Arab populations (Table 1).

Table 1. Sociodemographic characteristics and BMI of women diagnosed with endometriosis compared to matched controls.

\begin{tabular}{llcc}
\hline Patient Characteristics ${ }^{\mathbf{1}}$ (31 December 2015) & $\begin{array}{c}\text { Endometriosis } \\
(\boldsymbol{n}=\mathbf{6 1 4 6})\end{array}$ & $\begin{array}{c}\text { Controls } \\
(\boldsymbol{n}=\mathbf{2 4 , 5 7 2 )}\end{array}$ \\
\hline & Mean \pm SD & $40.4 \pm 8.0$ & $40.4 \pm 8.1$ \\
& $15-19$ & $52(0.8 \%)$ & $208(0.8 \%)$ \\
Age in 2015, y (matched) & $20-24$ & $167(2.7 \%)$ & $668(2.7 \%)$ \\
& $25-29$ & $428(7.0 \%)$ & $1712(7.0 \%)$ \\
& $30-34$ & $722(11.7 \%)$ & $2888(11.8 \%)$ \\
& $35-39$ & $1187(19.3 \%)$ & $4744(19.3 \%)$ \\
& $40-44$ & $1620(26.4 \%)$ & $6472(26.3 \%)$ \\
Residence area (matched) & $45-49$ & $1173(19.1 \%)$ & $4692(19.1 \%)$ \\
& $50-55$ & $797(13.0 \%)$ & $3188(13.0 \%)$ \\
& Central region & $4143(67.4 \%)$ & $16,572(67.4 \%)$ \\
& Northern & $1104(18.0 \%)$ & $4416(18.0 \%)$ \\
& Southern & $896(14.6 \%)$ & $3584(14.6 \%)$ \\
\hline
\end{tabular}


Table 1. Cont.

\begin{tabular}{llcc}
\hline Patient Characteristics $\mathbf{1}^{\mathbf{( 3 1} \text { December 2015) }}$ & $\begin{array}{c}\text { Endometriosis } \\
(\boldsymbol{n}=\mathbf{6 1 4 6 )}\end{array}$ & $\begin{array}{c}\text { Controls } \\
(\boldsymbol{n}=\mathbf{2 4 , 5 7 2})\end{array}$ \\
\hline \multirow{3}{*}{ SES } & Low (1-4) & $833(13.6 \%)$ & $4058(16.5 \%)$ \\
& Medium (5-6) & $2239(36.4 \%)$ & $9189(37.4 \%)$ \\
Population diversity & High (7-10) & $3059(49.8 \%)$ & $11,209(45.6 \%)$ \\
BMI & Missing & $15(0.2 \%)$ & $116(0.5 \%)$ \\
& Haredi (Jewish orthodox) & $157(2.6 \%)$ & $1223(5.0 \%)$ \\
\multirow{2}{*}{ BMI category } & Mean \pm SD & $245(4.0 \%)$ & $1268(5.2 \%)$ \\
& $<18.5$ & $24.8 \pm 5.2$ & $25.5 \pm 5.5$ \\
& $18.5-25.0$ & $305(5.0 \%)$ & $853(3.5 \%)$ \\
& $25.0-30.0$ & $2964(48.2 \%)$ & $10,553(42.9 \%)$ \\
& $\geq 30.0$ & $1364(22.2 \%)$ & $5425(22.1 \%)$ \\
& Missing & $818(13.3 \%)$ & $3796(15.4 \%)$ \\
\hline
\end{tabular}

${ }^{1}$ All $p$ values for unmatched variables are $<0.001$. SES, socioeconomic status; BMI, body mass index.

Infertility was present in $36.9 \%$ of women with endometriosis (Table 2), corresponding to an OR of 3.3 (95\% CI: 3.1-3.5), adjusting for SES and BMI (Figure 1). Women aged 40-44 had the highest lifetime prevalence of infertility (49.9\% vs. $21.7 \%)$. Chronic comorbidities (CVD, hypertension, diabetes, cancer, and CKD) were significantly more prevalent among women with endometriosis, with ORs ranging from 1.2 to 1.6 (Figure 1). Women with endometriosis also had a significantly higher prevalence of irritable bowel syndrome and appendicitis-conditions with potentially overlapping abdominal pain symptoms, where the distinction between comorbidity and misdiagnosis is often challenging (Table 2 and Figure 1).

Table 2. Comorbidities among women diagnosed with endometriosis compared to matched controls.

\begin{tabular}{llcc}
\hline \multirow{2}{*}{ Patient Characteristics (31 December 2015) } & $\begin{array}{c}\text { Endometriosis } \\
(\boldsymbol{n}=\mathbf{6 1 4 6 )}\end{array}$ & $\begin{array}{c}\text { Controls } \\
(\boldsymbol{n}=\mathbf{2 4 , 5 7 2 )}\end{array}$ \\
\hline \multirow{5}{*}{ Infertility } & All ages 15-55 & $2269(36.9 \%)$ & $3790(15.4 \%)$ \\
& $15-30$ & $80(12.4 \%)$ & $92(3.6 \%)$ \\
& $30-34$ & $218(30.2 \%)$ & $356(12.3 \%)$ \\
Conditions with overlapping & $35-39$ & $538(45.3 \%)$ & $866(18.3 \%)$ \\
symptoms & $40-44$ & $808(49.9 \%)$ & $1403(21.7 \%)$ \\
& IBD & $113(1.8 \%)$ & $262(1.1 \%)$ \\
& IBS & $92(1.5 \%)$ & $149(0.6 \%)$ \\
Chronic comorbidities & Appendicitis & $114(1.9 \%)$ & $188(0.8 \%)$ \\
& CVD & $222(3.6 \%)$ & $551(2.2 \%)$ \\
& Hypertension & $467(7.6 \%)$ & $1531(6.2 \%)$ \\
& Diabetes & $155(2.5 \%)$ & $550(2.2 \%)$ \\
CCI & Cancer & $240(3.9 \%)$ & $703(2.9 \%)$ \\
& CKD & $144(2.3 \%)$ & $389(1.6 \%)$ \\
& Mean \pm SD & $0.39 \pm 0.82$ & $0.29 \pm 0.68$ \\
Smoking & 1 & $912(14.8 \%)$ & $3023(12.3 \%)$ \\
& 2 & $396(6.4 \%)$ & $1299(5.3 \%)$ \\
\hline All $p$ values are $<0.05$, except for diabetes and COPD. IBD, inflammatory bowel disease; IBS, irritable bowel
\end{tabular}
syndrome; CVD, cardiovascular disease; CKD, chronic kidney disease; CCI, Deyo-Charlson comorbidity index.

\subsection{Healthcare Resource Utilization and Direct Medical Costs}

Women with endometriosis were significantly more likely than controls to have seen a gynecologist or other PCP within the year. Almost $20 \%$ of endometriosis patients visited a gynecologist at least 5 times during the year, 1.6 times as high as controls $(p<0.05$ for 
adjusted OR). Significantly higher annual rates of admission for hospitalization or ER visits were observed among endometriosis patients compared to controls. Women with endometriosis were more than twice as likely to have been hospitalized at least once, and three times as likely to have been hospitalized at least twice. ORs adjusted for SES and BMI are presented in Table 3.

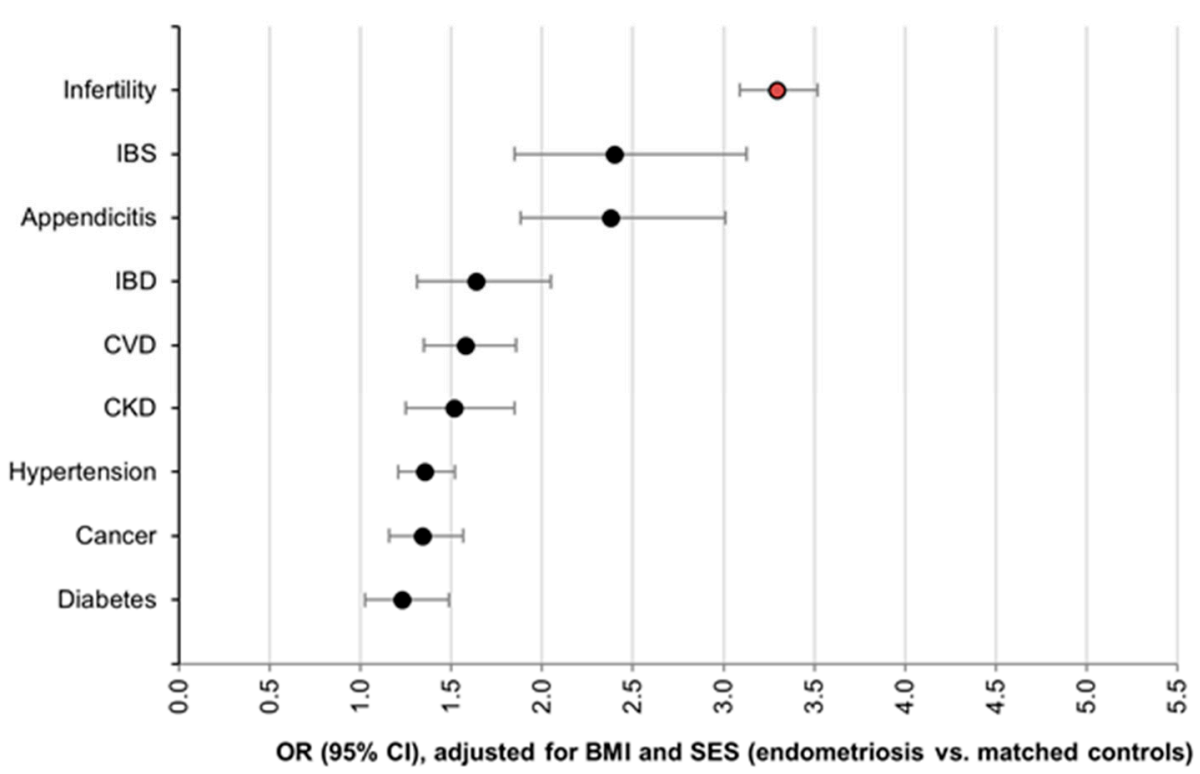

Figure 1. Odds ratios for comorbidities among women diagnosed with endometriosis compared to matched controls, adjusted for SES and BMI (lifetime prevalence).

Oral contraceptive use was $23.6 \%$ (vs. 15.6\%) in the past year, and $71.0 \%$ (vs. $53.2 \%$ ) for lifetime use. Women aged 25-29 had the highest rates of oral contraceptive use in 2015: $86.4 \%$ and $73.4 \%$ among endometriosis patients and controls, respectively. The annual rate of insertion of a hormone-releasing IUD was similar in the two groups and was low overall. Gonadotropin use was three times as high among endometriosis patients compared to controls (Table 3). Pain medication use was significantly higher in the endometriosis group, particularly for narcotic-like medications (tramadol). In addition, $11.8 \%$ of women with endometriosis used antidepressants in the past year (vs. 8.6\% of controls). Adjusted ORs are presented in Table 3. Utilization of imaging procedures (MRI and US) was increased in the endometriosis group compared to controls. Overall, $42.2 \%$ of women with endometriosis had a pelvic/genital US, of which only 3.1\% underwent a dedicated endometriosis US (Table 3). Compared to controls, endometriosis patients were significantly more likely to have had CBC and LH or FSH testing. CA-125 and CA-15.3 testing was associated with adjusted ORs (95\% CI) of 5.9 (5.2-6.7) and 3.2 (2.6-3.9), respectively. Overall, endometriosis was associated with an excess in total per-person direct medical costs across all age groups (Figure 2) and with an age-adjusted OR of 1.75 (95\% CI 1.69-1.85).

\subsection{Burden among Adolescents and Young Women}

In the youngest age group, $15-19$ years, women with endometriosis $(n=52)$ were significantly $(p<0.05)$ more likely than controls $(n=208)$ to have seen a PCP $(76.9 \%$ vs. $46.2 \%)$ and/or gynecologist (57.7\% vs. 14.4\%), and to have used oral contraceptives (76.9\% vs. 9.6\%). Among women aged 20-24 y, smaller but significant differences were also seen in PCP (92.8\% vs. $83.1 \%)$ and specifically gynecologist $(76.6 \%$ vs. $54.8 \%)$ visit rates and use of oral contraceptives (83.8\% vs. $56.7 \%$ ). Use of pain medication was more likely among endometriosis patients than controls, for the age groups 15-19 y (19.2\% vs. 3.8\%) and 20-24 y (15.6\% vs. 5.7\%). Among women aged 20-24, endometriosis was also associated with significantly higher antidepressant use (7.8\% vs. 3.4\%). Median direct medical costs per person for endometriosis were twice those of controls in the youngest age groups (Figure 2). 
Table 3. Annual healthcare resource utilization of women diagnosed with endometriosis compared to matched controls.

\begin{tabular}{|c|c|c|c|c|}
\hline \multicolumn{2}{|c|}{ Annual Healthcare Resource Utilization } & \multirow{2}{*}{$\begin{array}{c}\begin{array}{c}\text { Endometriosis } \\
(n=6146)\end{array} \\
68.1 \%\end{array}$} & \multirow{2}{*}{$\begin{array}{c}\begin{array}{c}\text { Controls } \\
(n=24,572)\end{array} \\
55.5 \%\end{array}$} & \multirow{2}{*}{$\begin{array}{c}\text { Adj. OR }(95 \% \mathrm{CI}) \text { * } \\
1.7(1.6-1.8)\end{array}$} \\
\hline \multirow{3}{*}{ Visits to gynecologist } & $\geq 1$ visit & & & \\
\hline & $\geq 5$ visits & $19.3 \%$ & $13.2 \%$ & $1.6(1.5-1.7)$ \\
\hline & Median (IQR) & $1(0-4)$ & $1(0-3)$ & \\
\hline \multirow{3}{*}{$\begin{array}{l}\text { Visits to family physician or } \\
\text { pediatrician }\end{array}$} & $\geq 1$ visit & $94.8 \%$ & $89.6 \%$ & $1.9(1.7-2.2)$ \\
\hline & $\geq 5$ visits & $67.5 \%$ & $53.3 \%$ & $1.8(1.7-1.9)$ \\
\hline & $\overline{\text { Median (IQR) }}$ & $7(3-12)$ & $5(2-10)$ & \\
\hline \multirow{2}{*}{ Hospitalizations } & $\geq 1$ & $12.5 \%$ & $6.0 \%$ & $2.3(2.1-2.5)$ \\
\hline & $\geq 2$ & $3.0 \%$ & $1.0 \%$ & $3.2(2.6-3.9)$ \\
\hline \multirow{2}{*}{ ER admissions } & $\geq 1$ & $8.1 \%$ & $4.9 \%$ & $1.7(1.5-1.9)$ \\
\hline & $\geq 2$ & $1.9 \%$ & $1.0 \%$ & $1.9(1.5-2.3)$ \\
\hline \multicolumn{2}{|c|}{ Insertion of hormone-releasing IUD } & $1.2 \%$ & $1.2 \%$ & $0.9(0.7-1.2)$ \\
\hline \multirow{2}{*}{ Oral contraceptives } & Any & $23.6 \%$ & $15.6 \%$ & $1.8(1.6-1.9)$ \\
\hline & Progesterone-only & $4.8 \%$ & $2.8 \%$ & $1.8(1.5-2.0)$ \\
\hline \multirow[t]{3}{*}{ Hormonal med. } & Gonadotropins & $4.9 \%$ & $1.5 \%$ & $3.2(2.8-3.8)$ \\
\hline & Cox-2 inhibitors & $3.2 \%$ & $2.1 \%$ & $1.6(1.4-1.9)$ \\
\hline & NSAIDs & $9.7 \%$ & $6.5 \%$ & $1.6(1.4-1.8)$ \\
\hline \multirow[t]{3}{*}{ Pain medication } & PAR, ASA, or dipyrone & $7.8 \%$ & $6.0 \%$ & $1.4(1.2-1.5)$ \\
\hline & Codeine with PAR or ASA & $3.4 \%$ & $2.3 \%$ & $1.6(1.3-1.8)$ \\
\hline & Tramadol & $0.9 \%$ & $0.4 \%$ & $2.3(1.6-3.2)$ \\
\hline \multirow[t]{2}{*}{ Antidepressants } & Any type & $11.8 \%$ & $8.6 \%$ & $1.4(1.3-1.5)$ \\
\hline & MRI & $0.6 \%$ & $0.1 \%$ & $10.3(5.6-19.0)$ \\
\hline \multirow[t]{2}{*}{ Imaging } & TVUS/pelvic/genital US & $\begin{array}{l}41.1 \% \\
(150 \%)\end{array}$ & $30.4 \%$ & $1.6(1.5-1.7)$ \\
\hline & E-TVUS & $3.1 \%$ & $0.0 \%^{+}$ & $29.5(19.4-44.8)$ \\
\hline \multirow{6}{*}{ Laboratory testing } & LH or FSH & $16.4 \%$ & $9.3 \%$ & $1.9(1.7-2.0)$ \\
\hline & CA-125 & $10.9 \%$ & $2.0 \%$ & $5.9(5.2-6.7)$ \\
\hline & CA-15.3 & $2.9 \%$ & $0.9 \%$ & $3.2(2.6-3.9)$ \\
\hline & CBC & $73.2 \%$ & $62.2 \%$ & $1.6(1.5-1.7)$ \\
\hline & $\mathrm{HG} \leq 11$ & $50.4 \%$ & $43.4 \%$ & $1.3(1.2-1.4)$ \\
\hline & Iron & $31.2 \%$ & $24.5 \%$ & $1.4(1.3-1.5)$ \\
\hline
\end{tabular}

ER, emergency room; IUD, intrauterine device; NSAID, nonsteroidal anti-inflammatory drug; PAR, paracetamol; ASA, acetylsalicylic acid; SSRI, selective serotonin reuptake inhibitor; LH, luteinizing hormone; FSH, folliclestimulating hormone; CA-125, cancer antigen 125; MRI, magnetic resonance imaging; US, ultrasound; TVUS, transvaginal US; E-TVUS, dedicated endometriosis TVUS; SES, socioeconomic status; BMI, body mass index; HG, Hemoglobin $\leq 11$ at least once within 5y; IQR; interquartile range. * OR from conditional logistic regression, adjusted for SES and BMI. † Includes one patient whose endometriosis diagnosis was confirmed by US in free text only. Boldface indicates statistical significance $(p<0.05)$.

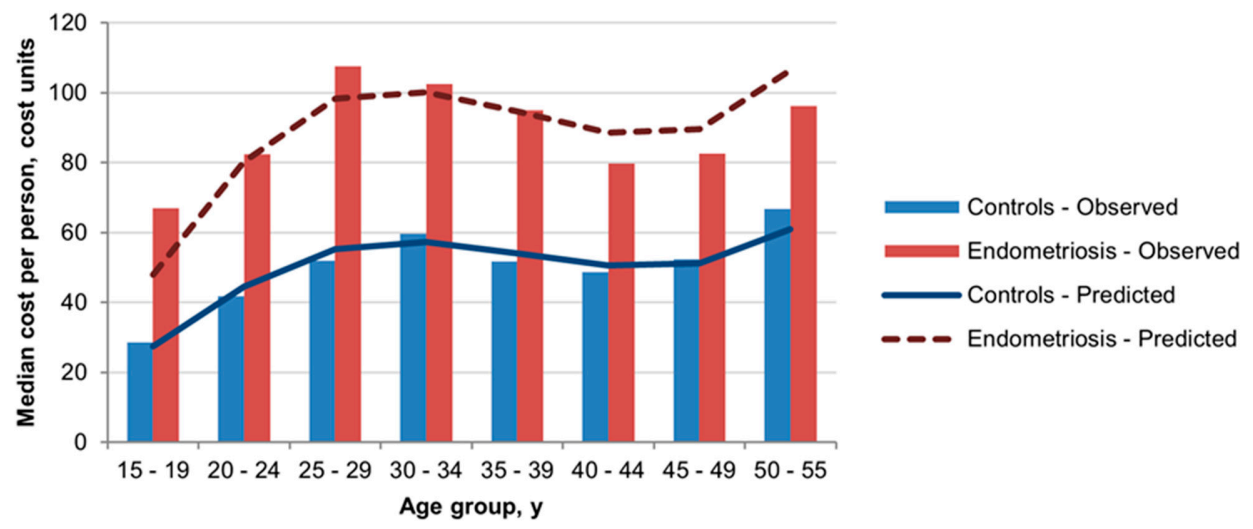

Figure 2. Observed and predicted median costs per person (endometriosis vs. controls) based on total annual direct medical costs in the local healthcare service and estimates from the generalized linear model adjusted for age. 


\section{Discussion}

The results of this study indicate that endometriosis was significantly associated with a higher burden of infertility, chronic comorbidities, utilization of healthcare services, pain medications, and antidepressants, and overall, 1.75-fold higher direct medical costs. The excess burden among young women aged 15-24 years reflects substantially higher utilization of gynecologist visits and oral contraceptives.

Patients diagnosed with endometriosis had higher HCRU than controls in all age groups. This is consistent with previous reports and is also associated with a higher economic and societal burden $[2,27,28]$. A meta-analysis of 24 studies showed an association between endometriosis and depressive symptoms which was mostly determined by chronic pelvic pain [29]. Patients with endometriosis are more likely to have associated comorbidities than controls. Previous studies [30-34] reported that women with endometriosis were more likely to have breast or ovarian cancer, autoimmune disease, or risk factors for cardiovascular disease. Fibromyalgia, interstitial cystitis, and IBD are also more commonly reported, possibly because of overlapping pain symptoms, resulting in a false or delayed diagnosis of endometriosis [35,36]. The co-occurrence of endometriosis and fibromyalgia is associated with an increased risk of anxiety or depression and HCRU [37]. We previously found a 10-fold increase in deep infiltrative endometriosis in patients with GI symptoms, suggesting the need to rule out endometriosis prior to performing any invasive GI procedures [38]. Our study found that women with endometriosis were more likely to have a lower BMI, and this inverse relationship has been demonstrated previously [39]. However, it should be mentioned that others have noted that the occurrence of obesity in women with endometriosis undergoing surgery was not a rare occurrence (7.4\%) [40].

The heterogeneity of HCRU in endometriosis patients is also influenced by the development of subsequent comorbidities [41]. Increasing awareness may improve prevention and early detection. This is particularly true for the younger patient population since their pain-related symptoms may eventually result in infertility [42], incurring additional costs [43]. Fuldeore et al. speculated that older women may be more accustomed to or tolerant of painful symptoms over time and therefore reported less often to a healthcare facility [31]. This is plausible but may be less apparent in our population as gynecologist visits were more frequent in women with endometriosis compared to controls across all age groups. High rates of HCRU may also occur in cases of delayed diagnosis of endometriosis. In one retrospective analysis, over a third of women were referred for repeated consultations, and ultrasound was helpful in diagnosing endometriosis in only $10.6 \%$ of women [44]. However, inexperienced investigators may yield false negative results, providing false reassurance, and contributing to the diagnostic delay.

In this study, we found a specific increase in HCRU in the younger population, similar to previous work [15]. It has been reported that $20-40 \%$ of adolescents reported missing school or declining performance and concentration due to their pelvic symptoms $[45,46]$ as well as increased comorbid anxiety and depression [47]. The negative impact that chronic pain has on mental health may explain the increased use of antidepressants. Awareness of this association between dysmenorrhea and mental health in adolescents is warranted. Earlier diagnosis in the adolescent community may reduce the level of depression and improve quality of life [47]. Additionally, earlier diagnosis may also influence HCRU in this population for better or worse. For example, local excision of endometriosis lesions has been associated with higher rates of reoperation, whereas hysterectomy has been associated with lower reoperation rates [48].

Our clinical setup is based on universal health coverage with high access to PCPs and treatment. The main strength of this study is the large, validated population-based database representing an average-risk population, rather than symptomatic patients at dedicated endometriosis or infertility clinics. For these reasons, our findings related to clinical characteristics and comorbidities may be generalizable to similar populations worldwide. Previous studies evaluating the impact of individual comorbidities on healthcare spending have relied on claims analysis only [41]. 
There are several limitations in this retrospective database study. Case ascertainment was based entirely on physician codes, and patients were included without confirmation by surgery or imaging. Most patients in this setting would be followed up in the community without surgical intervention. Some patients may not have been captured if the physician did not enter the diagnosis, in which case the actual prevalence may be higher, as previously discussed [7].

HCRU may have been affected by treatment type and duration, and women in the control group may also include those with symptomatic but undiagnosed disease. This may lead to underestimation of the disparity in symptomatic burden between the groups. The likelihood that women are experiencing symptoms years prior to diagnosis results in an inherent limitation. The symptomatic occurrence may be greater than symptomatic diagnosis, potentially enabling some endometriosis patients to be included in the control group. Autoimmune diseases were defined according to at least one ICD-9 diagnosis code from any physician, so misclassification of suspected disease is possible [5,33,34]. Previous studies have shown that women diagnosed with endometriosis were more likely than controls to be diagnosed with IBS, IBD, or other comorbidities, and there may be overlapping symptoms $[5,33,34,41]$, underscoring the challenge of distinguishing between misdiagnosis and comorbidity.

In conclusion, women with a diagnosis of endometriosis have a significantly higher burden of infertility and chronic comorbidities, increased HCRU, and excess costs, particularly younger patients whose healthcare needs may differ widely from those of otherwise healthy women.

Author Contributions: Conceptualization, V.H.E.; methodology, V.H.E., G.C., C.W.; software, C.W.; validation, V.H.E. and C.W.; formal analysis, V.H.E., D.H.D., C.W.; investigation, C.W.; resources, V.H.E.; data curation, V.H.E., D.H.D., C.W.; writing-original draft preparation, V.H.E. and C.W.; writing-review and editing, V.H.E., D.H.D., G.C., V.S., C.W.; visualization, V.H.E. D.H.D.; supervision, V.H.E.; project administration, V.H.E.; funding acquisition, none. All authors have read and agreed to the published version of the manuscript.

Funding: This research received no external funding.

Institutional Review Board Statement: This study was approved by the institutional review board (reference number 2016027).

Informed Consent Statement: Patient consent was waived due to the retrospective design of the study.

Conflicts of Interest: The authors declare no conflict of interest.

\section{References}

1. Eskenazi, B.; Warner, M.L. Epidemiology of endometriosis. Obstet. Gynecol. Clin. N. Am. 1997, 24, 235-258. [CrossRef]

2. Nnoaham, K.E.; Hummelshoj, L.; Webster, P.; d'Hooghe, T.; de Cicco Nardone, F.; de Cicco Nardone, C.; Jenkinson, C.; Kennedy, S.H.; Zondervan, K.T.; World Endometriosis Research Foundation Global Study of Women's Health consortium. Impact of endometriosis on quality of life and work productivity: A multicenter study across ten countries. Fertil. Steril. 2011, 96, 366-373.e8. [CrossRef] [PubMed]

3. Cramer, D.W.; Missmer, S.A. The Epidemiology of Endometriosis. Ann. N. Y. Acad. Sci. 2002, 955, 11-22. [CrossRef] [PubMed]

4. Viganò, P.; Parazzini, F.; Somigliana, E.; Vercellini, P. Endometriosis: Epidemiology and aetiological factors. Best Pr. Res. Clin. Obstet. Gynaecol. 2004, 18, 177-200. [CrossRef]

5. Ballard, K.D.; Seaman, H.E.; De Vries, C.S.; Wright, J.T. Can symptomatology help in the diagnosis of endometriosis? Findings from a national case-control study-Part 1. BJOG Int. J. Obstet. Gynaecol. 2008, 115, 1382-1391. [CrossRef]

6. Abbas, S.; Ihle, P.; Köster, I.; Schubert, I. Prevalence and incidence of diagnosed endometriosis and risk of endometriosis in patients with endometriosis-related symptoms: Findings from a statutory health insurance-based cohort in Germany. Eur. J. Obstet. Gynecol. Reprod. Biol. 2012, 160, 79-83. [CrossRef]

7. $\quad$ Eisenberg, V.H.; Weil, C.; Chodick, G.; Shalev, V. Epidemiology of endometriosis: A large population-based database study from a healthcare provider with 2 million members. BJOG Int. J. Obstet. Gynaecol. 2018, 125, 55-62. [CrossRef]

8. Harvey, J.; Warwick, I. Endometriosis. BMJ 2010, 340, 1416-1417. [CrossRef]

9. Hudelist, G.; Fritzer, N.; Thomas, A.; Niehues, C.; Oppelt, P.; Haas, D.; Tammaa, A.; Salzer, H. Diagnostic delay for endometriosis in Austria and Germany: Causes and possible consequences. Hum. Reprod. 2012, 27, 3412-3416. [CrossRef] 
10. Agarwal, S.; Chapron, C.; Giudice, L.C.; Laufer, M.R.; Leyland, N.; Missmer, S.A.; Singh, S.S.; Taylor, H.S. Clinical diagnosis of endometriosis: A call to action. Am. J. Obstet. Gynecol. 2019, 220, 354.e1-354.e12. [CrossRef]

11. Giudice, L.C. Clinical practice. Endometriosis. N. Engl. J. Med. 2010, 362, 2389-2398. [CrossRef]

12. Falcone, T.; Lebovic, D.I. Clinical Management of Endometriosis. Obstet. Gynecol. 2011, 118, 691-705. [CrossRef] [PubMed]

13. Johnson, N.P.; Hummelshoj, L.; Consortium, W.E.S.M.; Abrao, M.; Adamson, G.; Allaire, C.; Amelung, V.; Andersson, E.; Becker, C.; Birna Árdal, K. Consensus on current management of endometriosis. Hum. Reprod. 2013, 28, 1552-1568. [CrossRef] [PubMed]

14. Ballard, K.D.; Lowton, K.; Wright, J. What's the delay? A qualitative study of women's experiences of reaching a diagnosis of endometriosis. Fertil. Steril. 2006, 86, 1296-1301. [CrossRef] [PubMed]

15. Hirsch, M.; Dhillon-Smith, R.; Cutner, A.S.; Yap, M.; Creighton, S.M. The Prevalence of Endometriosis in Adolescents with Pelvic Pain: A Systematic Review. J. Pediatr. Adolesc. Gynecol. 2020, 33, 623-630. [CrossRef] [PubMed]

16. Cohen, R. Membership in Sick Funds 2013; National Insurance Institute of Israel: Jerusalem, Israel, 2014.

17. Eisenberg, V.H.; Arbib, N.; Schiff, E.; Goldenberg, M.; Seidman, D.S.; Soriano, D. Sonographic Signs of Adenomyosis Are Prevalent in Women Undergoing Surgery for Endometriosis and May Suggest a Higher Risk of Infertility. BioMed Res. Int. 2017, 2017, 8967803. [CrossRef]

18. Pinzauti, S.; Lazzeri, L.; Tosti, C.; Centini, G.; Orlandini, C.; Luisi, S.; Zupi, E.; Exacoustos, C.; Petraglia, F. Transvaginal sonographic features of diffuse adenomyosis in 18-30-year-old nulligravid women without endometriosis: Association with symptoms. Ultrasound Obstet. Gynecol. 2015, 46, 730-736. [CrossRef]

19. Brinton, L.A.; Trabert, B.; Shalev, V.; Lunenfeld, E.; Sella, T.; Chodick, G. In vitro fertilization and risk of breast and gynecologic cancers: A retrospective cohort study within the Israeli Maccabi Healthcare Services. Fertil. Steril. 2013, 99, 1189-1196. [CrossRef]

20. Shalev, V.; Chodick, G.; Goren, I.; Silber, H.; Kokia, E.; Heymann, A.D. The use of an automated patient registry to manage and monitor cardiovascular conditions and related outcomes in a large health organization. Int. J. Cardiol. 2011, 152, 345-349. [CrossRef]

21. Chodick, G.; Heymann, A.D.; Shalev, V.; Kookia, E. The epidemiology of diabetes in a large Israeli HMO. Eur. J. Epidemiol. 2003, 18, 1143-1146. [CrossRef]

22. Weitzman, D.; Chodick, G.; Shalev, V.; Grossman, C.; Grossman, E. Prevalence and Factors Associated with Resistant Hypertension in a Large Health Maintenance Organization in Israel. Hypertension 2014, 64, 501-507. [CrossRef] [PubMed]

23. Coresh, J.; Turin, T.; Matsushita, K.; Sang, Y.; Ballew, S.; Appel, L.J.; Arima, H.; Chadban, S.J.; Cirillo, M.; Djurdjev, O.; et al. Decline in Estimated Glomerular Filtration Rate and Subsequent Risk of End-Stage Renal Disease and Mortality. JAMA J. Am. Med Assoc. 2014, 311, 2518-2531. [CrossRef] [PubMed]

24. Canis, M.; Donnez, J.G.; Guzick, D.S.; Halme, J.K.; Rock, J.A.; Schenken, R.S.; Vernon, M.W. Revised American Society for Reproductive Medicine classification of endometriosis: 1996. Fertil. Steril. 1997, 67, 817-821. [CrossRef]

25. Deyo, R.A.; Cherkin, D.C.; Ciol, M.A. Adapting a clinical comorbidity index for use with ICD-9-CM administrative databases. J. Clin. Epidemiol. 1992, 45, 613-619. [CrossRef]

26. Chodick, G.; Porath, A.; Alapi, H.; Sella, T.; Flash, S.; Wood, F.; Shalev, V. The direct medical cost of cardiovascular diseases, hypertension, diabetes, cancer, pregnancy and female infertility in a large HMO in Israel. Health Policy 2010, 95, 271-276. [CrossRef]

27. Simoens, S.; Dunselman, G.; Dirksen, C.; Hummelshoj, L.; Bokor, A.; Brandes, I.; Brodszky, V.; Canis, M.; Colombo, G.L.; DeLeire, T.; et al. The burden of endometriosis: Costs and quality of life of women with endometriosis and treated in referral centres. Hum. Reprod. 2012, 27, 1292-1299. [CrossRef]

28. Fuldeore, M.; Yang, H.; Du, E.X.; Soliman, A.M.; Wu, E.Q.; Winkel, C. Healthcare utilization and costs in women diagnosed with endometriosis before and after diagnosis: A longitudinal analysis of claims databases. Fertil. Steril. 2015, 103, 163-171. [CrossRef]

29. Gambadauro, P.; Carli, V.; Hadlaczky, G. Depressive symptoms among women with endometriosis: A systematic review and meta-analysis. Am. J. Obstet. Gynecol. 2019, 220, 230-241. [CrossRef]

30. Rowlands, I.; Teede, H.; Lucke, J.; Dobson, A.; Mishra, G. Young women's psychological distress after a diagnosis of polycystic ovary syndrome or endometriosis. Hum. Reprod. 2016, 31, 2072-2081. [CrossRef]

31. Fuldeore, M.J.; Soliman, A.M. Prevalence and Symptomatic Burden of Diagnosed Endometriosis in the United States: National Estimates from a Cross-Sectional Survey of 59,411 Women. Gynecol. Obstet. Investig. 2017, 82, 453-461. [CrossRef]

32. Kvaskoff, M.; Mu, F.; Terry, K.L.; Harris, H.R.; Poole, E.M.; Farland, L.; Missmer, S.A. Endometriosis: A high-risk population for major chronic diseases? Hum. Reprod. Update 2014, 21, 500-516. [CrossRef] [PubMed]

33. Sinaii, N.; Cleary, S.D.; Ballweg, M.L.; Nieman, L.K.; Stratton, P. High rates of autoimmune and endocrine disorders, fibromyalgia, chronic fatigue syndrome and atopic diseases among women with endometriosis: A survey analysis. Hum. Reprod. 2002, 17, 2715-2724. [CrossRef] [PubMed]

34. Shafrir, A.L.; Palmor, M.C.; Fourquet, J.; DiVasta, A.D.; Farland, L.V.; Vitonis, A.F.; Harris, H.R.; Laufer, M.R.; Cramer, D.W.; Terry, K.L.; et al. Co-occurrence of immune-mediated conditions and endometriosis among adolescents and adult women. Am. J. Reprod. Immunol. 2021, 86, e13404. [CrossRef] [PubMed]

35. Steege, J.F.; Siedhoff, M.T. Chronic Pelvic Pain. Obstet. Gynecol. 2014, 124, 616-629. [CrossRef]

36. Wu, C.; Chung, S.; Lin, H. Endometriosis increased the risk of bladder pain syndrome/interstitial cystitis: A population-based study. Neurourol. Urodyn. 2018, 37, 1413-1418. [CrossRef] 
37. Greenbaum, H.; Weil, C.; Chodick, G.; Shalev, V.; Eisenberg, V.H. Evidence for an association between endometriosis, fibromyalgia, and autoimmune diseases. Am. J. Reprod. Immunol. 2019, 81, e13095. [CrossRef]

38. Ben-Meir, L.C.; Soriano, D.; Zajicek, M.; Yulzari, V.; Bouaziz, J.; Beer-Gabel, M.; Eisenberg, V.H. The Association Between Gastrointestinal Symptoms and Transvaginal Ultrasound Findings in Women Referred for Endometriosis Evaluation: A Prospective Pilot Study. Ultraschall Med. 2020. [CrossRef]

39. Liu, Y.; Zhang, W. Association between body mass index and endometriosis risk: A meta-analysis. Oncotarget 2017, 8, 46928-46936. [CrossRef]

40. Raimondo, D.; Raimondo, I.; Degli Esposti, E.; Mattioli, G.; Mastronardi, M.; Petrillo, M.; Dessole, S.; Mabrouk, M.; Del Forno, S.; Arena, A.; et al. Feasibility and safety of laparoscopic approach in obese patients with endometriosis: A multivariable regression analysis. Arch. Gynecol. Obstet. 2020, 302, 665-670. [CrossRef]

41. Epstein, A.J.; Soliman, A.M.; Davis, M.; Johnson, S.J.; Snabes, M.C.; Surrey, E.S. Changes in Healthcare Spending After Diagnosis of Comorbidities Among Endometriosis Patients: A Difference-in-Differences Analysis. Adv. Ther. 2017, 34, 2491-2502. [CrossRef]

42. Janssen, E.; Rijkers, A.; Hoppenbrouwers, K.; Meuleman, C.; D’Hooghe, T. Prevalence of endometriosis diagnosed by laparoscopy in adolescents with dysmenorrhea or chronic pelvic pain: A systematic review. Hum. Reprod. Update 2013, 19, 570-582. [CrossRef] [PubMed]

43. Soliman, A.M.; Yang, H.; Du, E.X.; Kelley, C.; Winkel, C. The direct and indirect costs associated with endometriosis: A systematic literature review. Hum. Reprod. 2016, 31, 712-722. [CrossRef] [PubMed]

44. Pugsley, Z.; Ballard, K. Management of endometriosis in general practice: The pathway to diagnosis. Br. J. Gen. Pr. 2007, 57, 470-476.

45. Bush, D.; Brick, E.; East, M.C.; Johnson, N. Endometriosis education in schools: A New Zealand model examining the impact of an education program in schools on early recognition of symptoms suggesting endometriosis. Aust. N. Z. J. Obstet. Gynaecol. 2017, 57, 452-457. [CrossRef]

46. Sachedina, A.; Todd, N. Dysmenorrhea, Endometriosis and Chronic Pelvic Pain in Adolescents. J. Clin. Res. Pediatr. Endocrinol. 2020, 12 (Suppl. 1), 7-17. [CrossRef]

47. Sahin, N.; Kasap, B.; Kirli, U.; Yeniçeri, N.; Topal, Y. Assessment of anxiety-depression levels and perceptions of quality of life in adolescents with dysmenorrhea. Reprod. Health 2018, 15, 13. [CrossRef]

48. Shakiba, K.; Bena, J.F.; McGill, K.M.; Minger, J.; Falcone, T. Surgical Treatment of Endometriosis: A 7-year follow-up on the requirement for further surgery. Obstet. Gynecol. 2008, 111, 1285-1292. [CrossRef] 